\title{
Comentário à Pítica VIII 1-60
}

Gustavo Henrique Montes Frade Universidade Federal de Minas Gerais

ghmfrade@gmail.com

ABSTRACT: A commentary on the first three triads of Pindar's Pythian VIII. In the first triad, the poet uses the divine Hesykhia to relate sports, war and politics; he also indicates the dependence of the human excelence on divine action and uses the presence of gods to praise the champion. In the second triad, Pindar praises the champion's homeland and shows the relation between the athlete and the poet, a brief remark on poetry and its social function. The third triad is dedicated to the mythical speech of Amphiaraus about luck and the oscillations between winning and losing in human life.

KEYWORDS: Greek poetry; Pindar; choral lyric; epinician poetry; Pythian VIII.

Píndaro abre a ode com uma caracterização da 'Houxía, a Calma (v. 1 a 5):

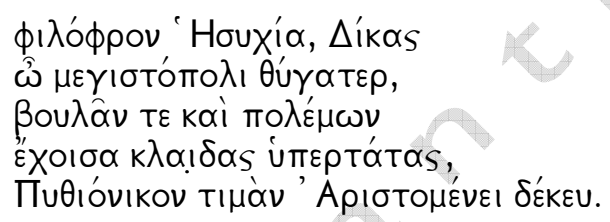

Gentil Calma, filha

da Justiça, ó engrandece-cidades!

Dos conselhos e guerras

tendo chaves supremas, recebe a honra de Aristômenes por vitória pítica. ${ }^{1}$

Segundo Lopes, "na Grécia antiga, o antropomorfismo divino parece ser firmemente enraizado nas crenças religiosas. Ele não é simples representação 'literária' ou 'homérica' dos deuses". ${ }^{2}$ Se o poeta trata a Calma como uma força divina que realiza ações, não é um procedimento estranho à religiosidade grega, afinal, “os deuses são as experiências mais intensas da realidade". ${ }^{3}$ Para Finley Jr., "é um tanto secundário se a presença divina nos poemas é ou não aquela de deuses conhecidos. Em suas diferentes formas, todos detêm em suas mãos as forças controladoras por trás dos homens e dos eventos". 4

\footnotetext{
${ }^{1}$ Todas as traduções de texto grego citadas neste artigo são de minha autoria.

${ }^{2}$ Cf. Lopes, A. O. O. D. L'effectivité improbable. Une étude de l'adverbe "reîa", de l'adjectif "chalepós" et des termes qui en dérivent dans les poèmes homériques. Tese de doutorado inédita em Filosofia. Strasbourg: Université Marc Bloch, 2009, p. 32.

${ }^{3}$ Cf. Lopes, op. cit., p. 40.

${ }^{4}$ Cf. Finley Jr., J. H. Pindar and Aeschylus. Cambridge: Harvard University Press, 1966, p. 168. 


\section{nuntius antiquus}

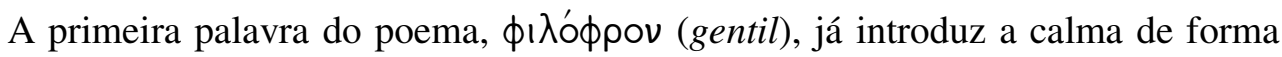
positiva. Em seguida, ela é apresentada como "filha da Justiça" e "a que engrandece as

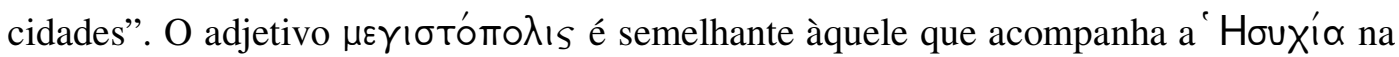
Quarta Olímpica: фı $\lambda_{\text {ómo }} \lambda_{\mathrm{s}}$, “a que ama as cidades”. A Calma tem assim um significado político e um efeito positivo sobre a cidade. Isso será desenvolvido nos v. 3 e 4: "Tendo as chaves supremas dos conselhos e das guerras". A calma promove o desenvolvimento da cidade, uma vez que é o primeiro recurso para obter resultados satisfatórios em qualquer situação política, já que “conselhos e guerras” abarcam as relações internas e externas, tanto na paz quanto na guerra. Calma se opõe a бтóoıs, a “dissensão social”, como no fragmento 109: ${ }^{5}$

Para colocar a comunidade num bom clima, que algum dos cidadãos procure o brilho da grandiosa Calma, tendo tirado do coração a rancorosa dissensão social, doadora de pobreza, odiosa nutriz.

Pela relação genealógica entre a Justiça e a Calma, a boa situação da cidade é também um produto da justiça (o que não exclui a guerra). Segundo Bundy, os v. 1 a 4 formam um catálogo das virtudes da 'Houxía como projeção divina protetora de uma entidade humana, análogo às convencionais listas de virtudes de indivíduos, clãs ou comunidades. $^{6}$

No v. 5, interrompendo a sequência de caracterizações, o poeta pede que a 'Houxía receba a honra correspondente à vitória de Aristômenes. Trata-se de um tipo de prece tradicionalmente usado para concluir unidades independentes na ode. ${ }^{7}$ Como o êxito é consagrada à Calma, há uma ligação entre os dois. Ela é enaltecida durante os quatro primeiros versos para proporcionar neste quinto uma espécie de clímax, em que o nome Aristômenes aparece, pela primeira vez no poema, em meio a palavras que só o elevam: honra, vitória pítica e o verbo recebe que efetiva a prece.

Os v. 6 e 7 retomam a caracterização:

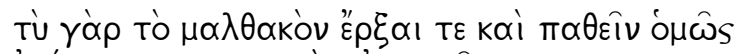

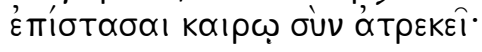

\footnotetext{
${ }^{5}$ Cf. Gentili, B.; Angeli-Bernardini, P.; Cingano, E.; Giannini, P. (org.). Pindaro: Le Pitiche. Verona: Arnoldo Mondadori, 1995, p. 563.

${ }^{6}$ Cf. Bundy, E. Studia Pindarica. Los Angeles: University of California Press, 1986, p. 27.

${ }^{7}$ Cf. Bundy, op. cit., p. 78.
} 
Porque tu sabes causar e receber suavidades igualmente, na oportunidade exata.

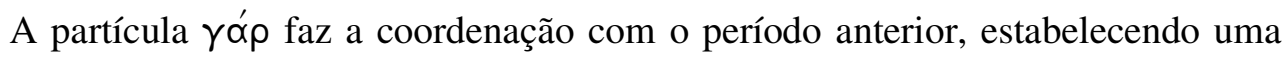
relação de causa. O pedido de aceitar a honra de Aristômenes é feito à Calma "porque ela sabe igualmente realizar e experimentar o que é suave com oportunidade exata". A interpretação desses versos varia consideravelmente. Pietro Giannini lê essa passagem como "a justificação do comportamento ambivalente da Hesykhía, mediante a oposição entre a atitude pacífica e a belicosa que ela assume". ${ }^{8}$ Crotty a interpreta como uma indicação do caráter de retribuição das ações da 'Houxía, que recompensa a gentileza ( тò $\mu \alpha \lambda \theta \alpha$ kóv) e pune o insolente (v. 8 a 14). ${ }^{9}$ Para Finley Jr., o trecho indica o poder certeiro de escolha: "Compreendes com tato perfeito tanto o dom quanto a aceitação de coisas gentis". ${ }^{10}$ Mais do que saber retribuir agrados, a Calma sabe quando é a ocasião certa de assumir uma postura ativa ou passiva. A ação que faz ou sofre é classificada como $\mu \alpha \lambda \theta \propto$ kóv (mole), termo que indica a flexibilidade de mudança entre a postura ativa e a passiva e também a suavidade do agir preciso, "na oportunidade exata". A Calma proporciona a adaptação a situações e a precisão no agir. É possível ler esse trecho como uma reflexão sobre esse agir humano de forma geral, mas que serve especialmente à esfera política, que aparece nos v. 1 a 4 , e às atividades atléticas, introduzidas no v. 5 com "vitória pítica". A precisão e maleabilidade necessárias para obter resultados na atuação política, em meio às situações e aos interesses diversos, seriam semelhantes àquelas necessárias para obter-se vitória em uma disputa esportiva ou mesmo numa guerra.

Assim, a estrofe termina enfatizando a associação entre a 'Houxí e o vencedor. Lefkowitz considera que a Calma é usada para descrever o estado do vencedor após seu sucesso, ${ }^{11}$ mesmo num sentido mais geral de descanso e tranquilidade depois de um esforço físico em disputa atlética. ${ }^{12}$ Entretanto, parece ser uma condição necessária para a vitória nos campos de ação relacionados nessa primeira estrofe: a política, a guerra e a atividade esportiva.

\footnotetext{
${ }^{8}$ Cf. Gentili et alii, op. cit., p. 564.

${ }^{9}$ Cf. Crotty, K. Song and action. Baltimore: The Johns Hopkins University Press, 1982, p. 17.

${ }^{10}$ Cf. Finley Jr., op. cit., p. 152.

${ }^{11}$ Cf. Lefkowitz, M. Pindar's "Pythian 8". The Classical Journal. Northfield, n. 72, p. 209-221, 1976/ 1977, p. 209-21.

${ }^{12}$ Cf. Lefkowitz, M. Influential Fictions in the Scholia to Pindar's "Pythian 8". Classical Philology. Chicago, vol. LXX, n. 3, p. 177, jul. 1975.
} 


\section{nuntius antiquus}

A antístrofe se inicia com tù $\delta$ '. A partícula $\delta^{\prime} \varepsilon$ tem aí uma função adversativa em relação à estrofe. Há uma mudança radical no tratamento da 'Houxía, que agora aparece como um agente personificado belicoso que pune (v. 8 a 12):

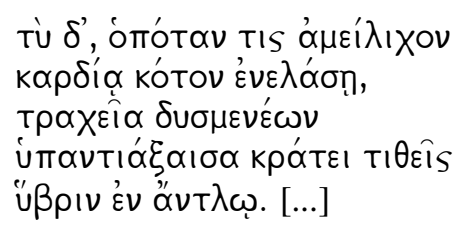

Tu, quando quer que alguém um amargo rancor no coração incuta, áspera, vindo de encontro à força dos inimigos colocas a arrogância na sentina. [...]

A conjunção ómóta $v$, "quando quer que", pelo emprego do subjuntivo, funciona quase como "toda vez que", indicando a eficácia da ação. Esta vem reforçada pelo pronome indeterminado TIS. "Qualquer um" pode ser objeto da ação da Calma, no

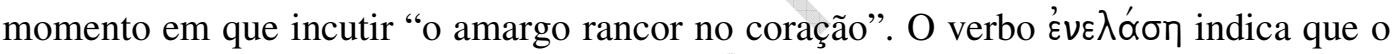
rancor não simplesmente se encontra no coração, sede das emoções, mas foi para lá impelido e lá é mantido pela própria ação e responsabilidade de quem é rancoroso.

Nos v. 10, 11 e 12, Píndaro conta como a Calma age sobre quem tem rancor. Ela

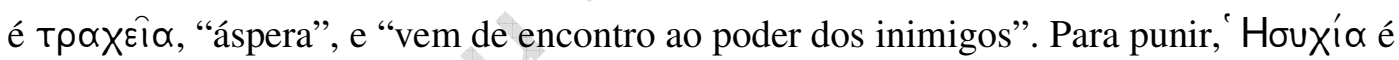
hostil e enfrenta o кра́тоs desses inimigos. Kра́тоs, segundo Benveniste, tem os valores de "superioridade; prevalência" em relação à força ou habilidade e também de “poder (de autoridade)", utilizado em Homero em relação a situações de batalha e na assembleia. ${ }^{13}$ Essa ideia de "predomínio" mostra que a ação da üßpı acontece quando o agente está submetido ao domínio de forças contrárias à Calma.

Como se sabe, o termo üßpıs não indica a simples ideia de "arrogância". Segundo Gernet, é um termo moral que, "no direito penal, designa a ofensa ao indivíduo e, na época clássica, exprime o elemento espiritual do delito, a vontade criminal do indivíduo". ${ }^{14}$ Em Homero, é o princípio de desorganização que se opõe à estabilidade

\footnotetext{
${ }^{13}$ Cf. Benveniste, E. Le Vocabulaire des Instituitions Indo-Européennes. 2. Pouvoir, droit, religion. Paris: Les Éditions de Minuit, 1969, p. 76-77.

${ }^{14} \mathrm{Cf}$. Gernet, L. Recherches sur le développement de la pensée juridique et morale en Grèce. Paris: Albin Michel, 2001, p. 17.
} 


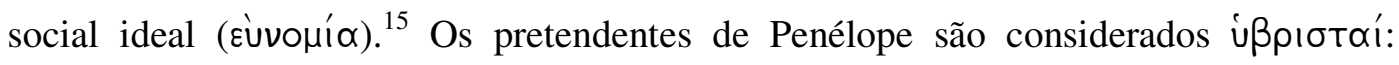
"estrangeiro, de fato, chegas à terra que procuras. Arrogantes e insensatos homens a detêm" (Canto XXIV, v. 281 e 282) e a arrogância (üßpıs) e violência (ßín) deles alcança o céu (Canto XV, v. 329). Em Hesíodo, torna-se um termo muito forte e muito geral: sinônimo de ơvouía, ele se aplica já aos grandes criminosos da gesta dos deuses e indica a violência brutal, que torna a vida social impossível. ${ }^{16} \mathrm{Na}$ Teogonia (306-307), o termo úßpıotńs é usado para caracterizar Tífon (que aparece no v. 16 da Oitava

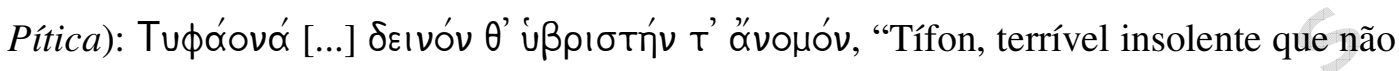
segue as leis”. Para Gernet, Píndaro rejeita, no passado das lendas, a imagem patética da üßpıs, acumulando alusões a desordens insolentes que, em tempos já passados, os grandes ímpios e os monstros ilustres levantaram contra a divindade. Gernet considera que, nesse aspecto, a poesia coral é penetrada de otimismo: de preferência, ela canta a üßpıs vencida. Ela exalta aqueles que sabem, sob a influência da hereditariedade e das tradições familiares, seguir o caminho longe das rotas da üßpıs. ${ }^{17}$ Nisso a lírica coral segue a épica.

Ao se aproximar do poder dos inimigos, a Calma "coloca a arrogância na

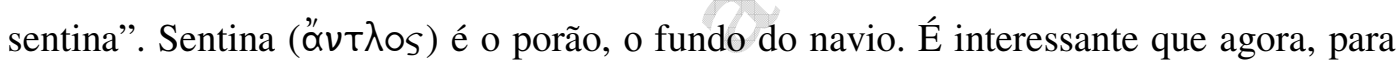

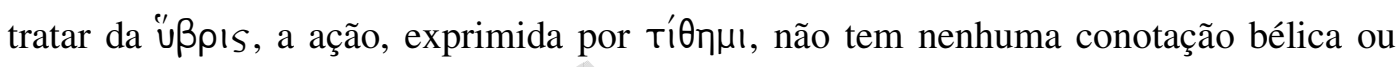
violenta, para não aproximá-la da Calma e de sua ação vigorosa. A "arrogância" é característica de quem mantém o kótos, "ressentimento". Não é um simples sentimento de insatisfação, mas algo mais profundo e renitente. A üßpıs, como será logo exemplificado pela figura de Porfírion, é a ação de alguém que não compreende o seu próprio lote e os limites que lhe cabe ocupar na vida.

Inundada por águas imundas, a sentina é o lugar que a Calma escolhe para deixar a arrogância. Como a estrofe já havia criado um contexto fortemente político, é possível compreender essa referência à sentina como uma alusão à imagem da cidade como um navio, que aparece desde Alceu (D 15 e A 6, ed. Gallavotti) e Arquíloco (56 D completado pelo Pap. Mus. Brit. 2625 A do s. III a.C.). ${ }^{18}$ A alegoria também aparece em Teógnis (v. 671-682) e continua importante na tragédia, como em Sete contra Tebas de Ésquilo (792-798) e na República de Platão (livro VI, 488a-499a). Nos versos de

\footnotetext{
${ }^{15}$ Cf. Gernet, op. cit., p. 24-25.

${ }^{16} \mathrm{Cf}$. Gernet, op. cit., p. 31.

${ }^{17}$ Cf. Gernet, op. cit., p. 41.

${ }^{18}$ Cf. Adrados, F. R. El mundo de la lírica griega antigua. Madrid: Alianza Editorial, 1981, p. 167-171. 


\section{nuntius antiquus}

Ésquilo, o mensageiro anuncia que a cidade conseguiu resistir ao ataque utilizando a palavra ớvт入os, com um sentido de água da sentina:

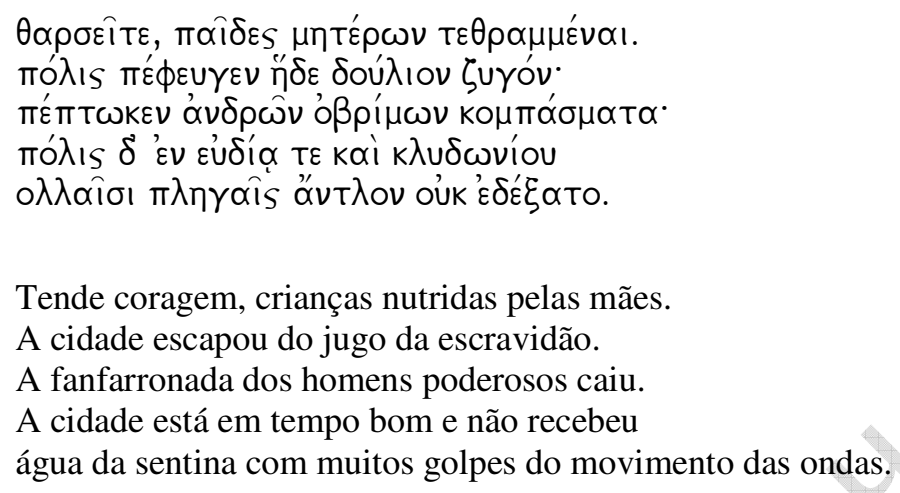

Tende coragem, crianças nutridas pelas mães. A cidade escapou do jugo da escravidão.

A fanfarronada dos homens poderosos caiu. A cidade está em tempo bom e não recebeu água da sentina com muitos golpes do movimento das ondas.

Segundo Gentili, a água da sentina é a onda de guerreiros armados invadindo a cidade. Se seus golpes não abriram fendas no casco, o assalto do inimigo falhou em quebrar os muros da cidade. ${ }^{19} \mathrm{~A}$ água suja da sentina é o que invade a cidade causando a degeneração da estrutura social.

Gentili também afirma que a relação analógica entre navio e cidade tem como base a estrutura do navio, com seus espaços internos repartidos de acordo com os mesmos critérios que se encontram por trás da organização política do espaço urbano. ${ }^{20}$ Dentro da estrutura política, o lugar que deve ser o da üßpıs é o pior possível e o mais distante do convés, que sedia o governo da cidade. ${ }^{21}$ Portanto, ela não é propriamente expulsa do navio de forma definitiva, permanecendo na vida política das cidades, já que pode eventualmente voltar para o convés. Parece-me que a precisão do termo náutico sobrepõe três imagens: a cidade como navio, o afogamento da arrogância, que deve ser suprimida, e a imundície da água como apreciação moral totalmente negativa da üßpıs.

Na sequência, Porfírion é o exemplo de arrogância (v. 12 a 14):

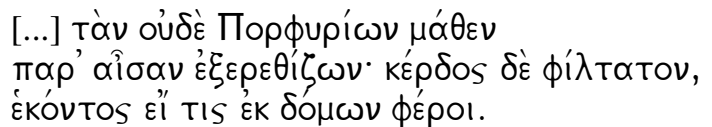

[...] Nem Porfírion a compreendeu, provocando-a contra o destino. O ganho é mais querido se alguém trouxer da casa de quem dá de bom grado.

\footnotetext{
${ }^{19}$ Cf. Gentili, B. Poetry and its public in Ancient Greece. From Homer to the fifth century. Translated with an introduction by A. Thomas Cole. London: Johns Hopkins Press, 1990, p. 199.

${ }^{20}$ Cf. Gentili, op. cit., p. 213.

${ }^{21}$ Cf. Gentili et alii, op. cit., p. 566.
} 
O gigante, que não é das figuras mitológicas mais recorrentes na literatura grega, aparece também na Biblioteca de Pseudo-Apolodoro (1,35-1,36):

Porfírion se atirou contra Héracles e Hera durante a luta [entre gigantes e deuses]. Zeus suscitou nele desejo por Hera, a qual, uma vez que ele rasgou as roupas e quis violentá-la, chamava socorro. Tendo-o Zeus fulminado, Héracles o matou a flechadas.

Apesar de não necessariamente conhecer o mito da mesma forma que a relatada na Biblioteca, Píndaro também associa Porfírion ao enfrentamento da ordem divina.

Tàv, usado como pronome, se refere a 'Houxía, a qual Porfírion "não compreendeu". Há uma contraposição entre a Calma que sabe agir e sofrer (v. 7) e a ignorância de Porfírion, que não a compreende. A provocação do gigante acontece pela falta de conhecimento, enquanto o conhecer é associado ao vencedor.

Aîoa tem um significado original de parte, lote. A partir dele, há as expressões

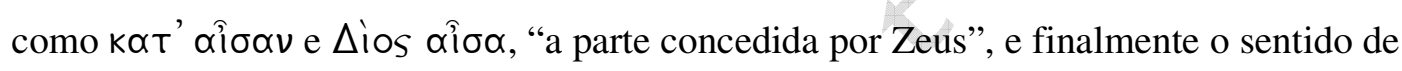
o que é destinado. ${ }^{22}$ A expressão $\pi \propto \rho$ ' $\propto \hat{\jmath} \sigma \alpha \nu$ tem forte carga religiosa e marca a ação do gigante como "contrária ao destino" ou "contrária à decisão divina". Essa é uma caracterização da ação da qual a Calma não participa: uma impiedade, um enfrentamento das leis divinas, que só leva a péssimos resultados.

Com a partícula $\delta \dot{\varepsilon}$, a sentença gnômica que fecha a antístofe contrapõe-se à situação de Porfírion. A partir dele se tira uma conclusão de que "o ganho é mais querido se alguém trouxer da casa de quem dá de bom grado”. Receber de bom grado, em oposição a tomar à força, também indica as recompensas das ações regidas pela Calma, tanto em acúmulo de riquezas materiais, quanto em boas relações humanas. Esse

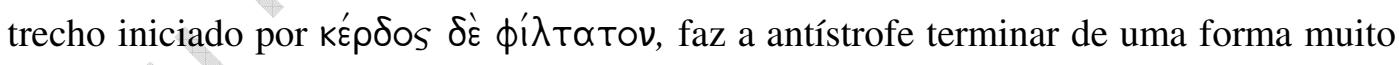
mais leve, após a ação bélica da Calma e a menção ao terrível destino do fracassado Porfírion. A expressão gnômica faz uma referência aos jogos: o vitorioso, que é coroado de bom grado e recebe a ode como homenagem, está na condição completamente oposta à do gigante.

O epodo se inicia com ßía, "violência", que aparece como o contrário de 'Houxía, assinalado pela partícula $\delta$ é (v. 14 a 17):

\footnotetext{
${ }^{22}$ Cf. Chantraine, P. Dictionnaire étymologique de la Langue Grecque. Histoire des mots. Paris: Éditions Klincksieck, 1968. Tome I, p. 238. 


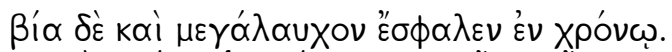

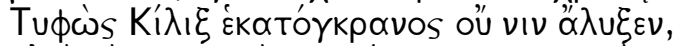

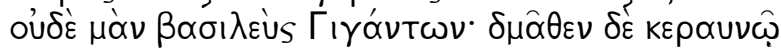

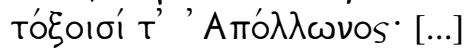

Violência abala até o orgulhoso com o tempo.

Tifos, cilício de cem cabeças, dela não escapou, nem, por certo, o rei dos gigantes: foram dominados pelo raio e arcos de Apolo. [...]

O verbo $\sigma \phi \alpha ́ \alpha \lambda \omega$ (abalar, derrubar) proporciona uma imagem que serve especialmente à luta. Eficaz como a Calma, a violência afeta até mesmo o orgulhoso. $\mathrm{O}$

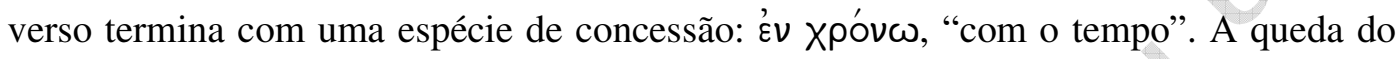
violento não vem imediatamente. A sentença gnômica propõe que quem fez uso da violência, mas ainda não recebeu essa espécie de punição, com o passar do tempo ainda será atingido.

$\mathrm{Na}$ sequência, Píndaro retoma o discurso mitológico. Tífon, o exemplo de ußpıotńs na Teogonia de Hesíodo (v. 306 a 307), é um filho da Terra, terrivelmente forte, com cem cabeças de serpente. Ele também atira fogo pelos olhos e lança diversos ruídos e vozes diferentes (820 a 885). De acordo com Hesíodo, ele teria poder para reinar sobre mortais e imortais se Zeus não estivesse com a mente afiada (838). Este, com suas armas (relâmpago, raio e trovão; v. 854), o derrota e o lança ao Tártaro. Na Oitava Pítica, apesar da extrema força, Tífon fracassa por agir com violência. É um exemplo de que esta derruba qualquer um que fizer uso dela. A longa denominação

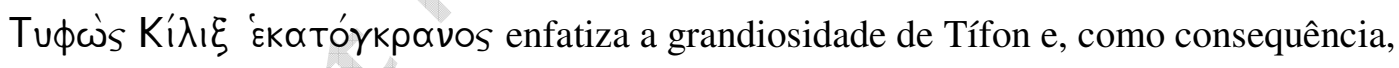
faz a ßía ainda mais potente, já que nem mesmo tal criatura pôde escapar dela. O v. 17 acrescenta a informação "nem o rei dos gigantes", retomando Porfírion para concluir o relato sobre o fim que recebem os usuários da força (em Ringkomposition, ${ }^{23}$ como lembra Giannini). Ambos "foram dominados pelo raio", arma característica de Zeus, "e pelos arcos de Apolo". A queda de quem é violento é realizada pelas armas, o que faz lembrar que, no v. 15, a própria violência provoca essa queda. Entretanto, a ação violenta de Zeus, de Apolo e da Calma (na antístrofe) é diferente da ßí $\alpha$ introduzida no v. 15 , pois esta é a ação de üßpıs, contrária à ordem divina. O simples uso da força bruta não aparece como contrário à Calma e pode ser usado como meio de fazer justiça.

\footnotetext{
${ }^{23}$ Cf. Gentili et alii, op. cit., p. 567.
} 


\title{
nuntius antiquus
}

Citar os deuses eleva o tom do discurso, preparando terreno para uma nova menção a Aristômenes, mais uma vez em momento de clímax. Apolo faz a ligação e contraposição entre o fracasso dos arrogantes e a glória do atleta triunfante (v. 17 a 19):

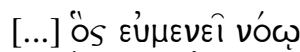

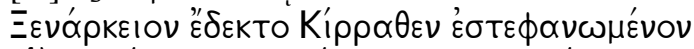

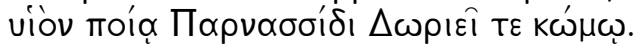 \\ [...] o qual com benévola mente \\ recebeu de Cirra o filho de Xenarces, coroado \\ com relva do Parnaso e dórica festividade.
}

Píndaro faz referência aos locais relacionados à vitória e às homenagens recebidas pelo atleta. Na planície de Cirra eram relizadas as corridas e disputas atléticas até talvez a segunda metade do século V, quando foi construído o estádio de Delfos. Parnaso é um monte localizado em Delfos, onde crescia louro, planta consagrada a Apolo. A festividade é dórica porque é realizada em Egina, ilha dórica e terra natal de Aristômenes. $^{24}$ Aqui há apenas uma breve alusão, mas, a partir do v. 21, o poeta se voltará com mais atenção à terra natal do atleta.

O deus Apolo desempenha um papel análogo ao da 'Houxía, recebendo o vitorioso e punindo os adversários. Ambos apenas reagem aos feitos dos outros, coroando o justo e punindo o injusto. ${ }^{25}$ É importante lembrar que a Calma é filha da Justiça e esta parece estar relacionada com a aceitação dos deuses e com a prática de ações que não sejam contrárias aos seus desígnios.

Nos v. 18 a 20, saindo da total derrota, aparece a vitória, com o que ela

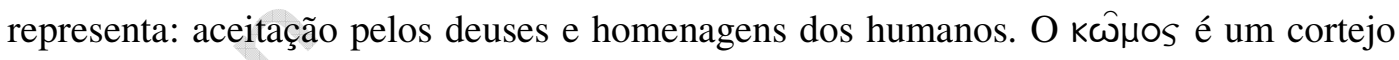
com Canto e dança. Toda essa glória do triunfo é de certa forma um resultado da Calma, posto que o vencedor já havia sido relacionado a ela. Nesse clímax da celebração da vitória, a 'Houxía é deixada de lado, dando lugar à homenagem pessoal ao vencedor.

O vencedor só é mencionado em momentos de clímax, preparados pela caracterização da Calma. Esta é necessária para que seja possível alcançar a vitória. Segundo Adrados, "quando a lírica se dirige ao deus, quer dizer, nas diversas variantes do hino, o tema do poder divino arrasta atrás de si o tema da debilidade e da penúria do

\footnotetext{
${ }^{24}$ Cf. Gentili et alii, op. cit., p. 568.

${ }^{25}$ Cf. Crotty, op. cit., p. 17-18. 


\section{nuntius antiquus}

homem". ${ }^{26}$ Segundo Finley Jr., a invocação à Houxía contém um senso de presença divina, misteriosa, meio escondida nos eventos, ainda que operativa por trás da peça visível da vida e da natureza. ${ }^{27}$ A prece que abre a Oitava Pítica não só associa a vitória e o vencedor à divindade, mas lembra que sem alguma presença divina ele não é capaz. Esse é o tema principal que será desenvolvido ao longo da ode.

A segunda tríade do poema é dedicada ao elogio de Aristômenes. Na estrofe, Píndaro enaltece a terra natal do campeão. Na antístrofe, mostra a grandeza do vencedor através do trabalho do poeta. O epodo homenageia a família do vitorioso.

O primeiro período da estrofe tem uma organização de palavras muito artificial (v. 21 a 24):

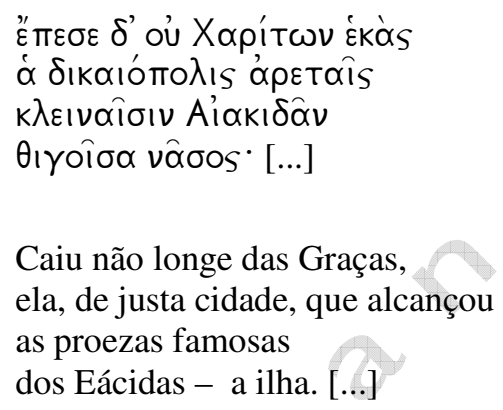

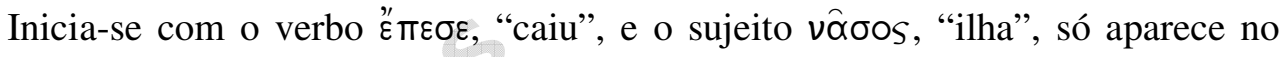
quarto verso. O texto, reorganizado para um entendimento mais claro, seria este: "a ilha de justa cidade, que alcança as proezas famosas dos Eácidas, não caiu longe das Graças". A menção dos Eácidas deixa claro que a ilha é Egina, terra natal de Aristômenes. Como a ilha é $\delta ı$ кı́ото $\lambda_{I}$, de cidade justa, deve-se lembrar que a justiça já havia sido mencionada nos primeiros versos do poema como mãe da Tranquilidade e, portanto, base para uma boa organização política. Não só o atleta, mas também a cidade apresenta excelência. $\mathrm{O}$ elogio da terra natal do vencedor, recorrente nas odes de Píndaro, estabelece uma relação de continuidade e integração entre a glória coletiva da cidade e a glória particular do atleta.

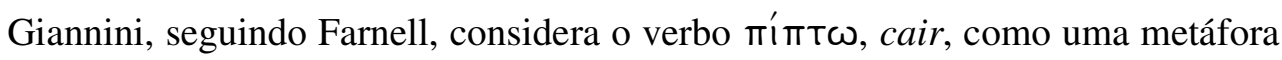
tirada do jogo de dados. ${ }^{28}$ É um cair involuntário em que o final da trajetória não pode ser previsto. Como se Egina estivesse perto das graças por efeito de algo que os homens

\footnotetext{
${ }^{26}$ Cf. Adrados, op. cit., p. 61.

${ }^{27}$ Cf. Finley Jr., op. cit., p. 166.

${ }^{28}$ Cf. Gentili et alii, op. cit., p. 569.
} 


\section{nuntius antiquus}

não podem controlar. As Graças (Xópıtes), na poesia de Píndaro, são diretamente associadas à criação poética. Aparentemente, elas presidem os cantos de vitória e são encarregadas de proclamá-lo. O papel das Graças parece ser, sobretudo, o de embelezar o assunto do canto que as Musas, mensageiras da onisciência divina, permitem ao poeta conhecer. $^{29}$ Não cair longe das graças significa, então, possuir feitos memoráveis imortalizados em poemas, como a vitória de Aristômenes e as "proezas" (atos de excelência) "famosas" (propagadas pelos cantos) "dos Eácidas" com as quais a ilha teve

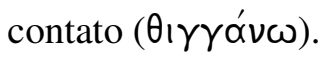

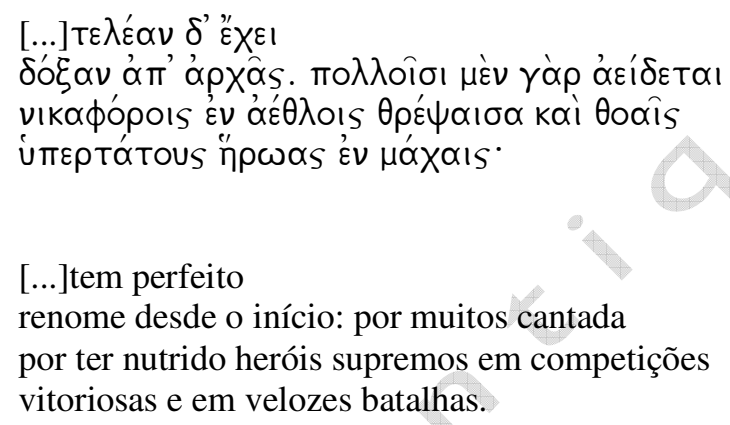

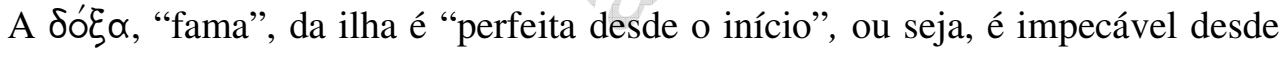
um passado remoto. O motivo dessa fama vem na sequência do v. 25: "Pois por muitos é cantada por ter nutrido heróis supremos em competições vitoriosas e em velozes batalhas". A glória para a cidade é ser pátria de homens excelentes, dignos de canto. A excelência, no caso, é o bom desempenho na guerra e nos jogos, já associados na primeira tríade do poema.

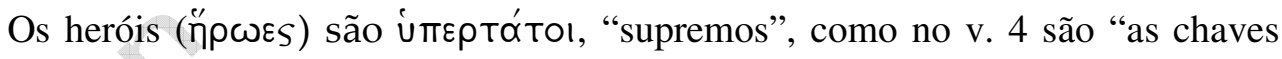
supremas dos conselhos e das guerras", que a Tranquilidade possui. A supremacia do herói, explicitada nos v. 26 e 27 como relativa às competições e batalhas, ao mesmo tempo remete ao v. 4, retomando um contexto político. Assim o herói, que realiza façanhas na guerra e nos jogos, é considerado como um elemento de importância política. Esses heróis, e consequentemente a cidade, têm a fama e o valor efetivamente reconhecidos através dos poemas. Ao louvar a cidade, Píndaro estabelece a importância política do herói e do poeta. Além de renovar o sentido original dos primitivos cantores,

\footnotetext{
${ }^{29}$ Cf. Duchemin, J. Pindare, poète et prophete. Paris: Les Belles Lettres, 1955, p. 54-60. 30
} 


\section{nuntius antiquus}

consagrados à glorificação dos grandes feitos, como indicava Jaeger, ${ }^{30}$ o resultado conjunto da ação do herói e da palavra do poeta promove a glorificação da cidade, assim como a Tranquilidade promove o sucesso da cidade tanto em guerras quanto em conselhos.

Toda essa justificativa é importante porque já autores antigos, como Xenófanes, criticam a importância dada aos atletas campeões. O assunto é tratado em versos elegíacos no fragmento 2 West:

Se, com a velocidade dos pés, alguém alcançasse a vitória ou competindo no pentatlo - ali onde é o santuário de Zeus perto da corrente do Pisa em Olímpia - ou lutando, ou sabendo o pugilato doloroso, ou a terrível competição a que chamam de pancrácio, para os cidadãos, seria mais glorioso de se ver.

Alcançaria lugar privilegiado, em evidência, nas disputas, seu alimento seria gasto público da cidade e um presente, que seria para ele um tesouro. Ou se com cavalos... tudo isso obteria, não sendo digno como eu: pois é melhor do que a força de homens e cavalos a nossa sabedoria. Mas em vão dá muito valor a isso. Não é justo preferir a força à boa sabedoria.

Pois nem se um bom pugilista estiver com o povo, nem se fizer pentatlo, nem luta-livre, nem se com a velocidade dos pés, o que é mais honrado, quantas obras de força na luta realizasse, por esse motivo a cidade não estaria em melhor ordem. Pequena seria a alegria para a cidade por causa disso, se alguém, competindo, vencesse perto das margens do Pisa: pois não engrandece $\mathrm{o}$ interior da cidade.

Para Xenófanes, a vitória nos jogos, além de não trazer nenhum benefício à cidade, provoca gastos que poderiam ser evitados. O povo deixa de valorizar o mais importante, a verdadeira excelência (no caso, a sabedoria), para honrar aqueles com melhor capacidade física ou que puderam criar cavalos melhores. O que Xenófanes critica no sexto verso do fragmento - "para os cidadãos, seria mais glorioso de se ver" é o que Píndaro reforça no v. 28, que abre a antístrofe: "Essas coisas além do mais entre os homens se distinguem". Trata-se da admiração que o vencedor pode provocar. Para Píndaro, e para a mentalidade aristocrática com a qual ele está comprometido, isso valoriza a cidade, reafirmando a grandeza da cidade perante o mundo grego.

${ }^{30}$ Cf. Jaeger, W. Paideia: a formação do homem grego. Tradução de Artur M. Parreira. São Paulo: Martins Fontes, 2001, p. 225. 


\section{nuntius antiquus}

Na sequência, a antístrofe (28 a 35):

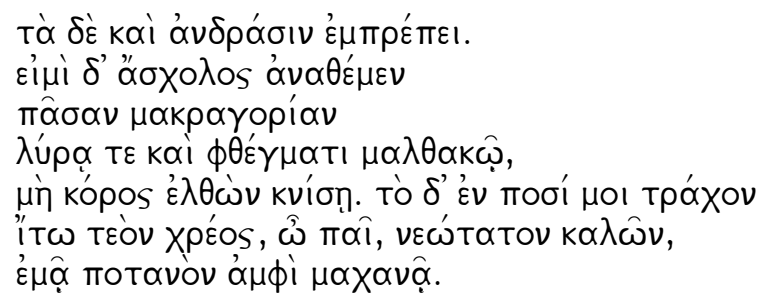

Isso além do mais entre os homens se distingue.

Falta-me disponibilidade para alçar todo o longo discurso

com lira e voz suave

para que a saciedade, vindo, não incomode. O que corre nos meus pés, o dever, que parta para contigo, ó jovem, o mais novo dos belos, alado por meu engenho.

Píndaro utiliza um recurso tradicional para valorizar a conquista de Aristômenes.

Como comenta Bundy:

O laudator é frequentemente ớxo入os (sem tempo livre) diante de um aspecto de seu tema [...]. Na oitava pítica, 30 a 35, encontrando-

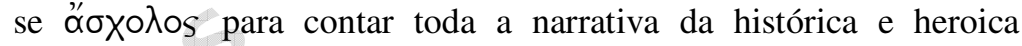
grandeza de Egina, ele escolhe tratar apenas de sua última glória, a recente vitória de Aristômenes. ${ }^{31}$

O poeta não tem disponibilidade para cantar todas as glórias de Egina porque a lista seria excessivamente longa, como a lista de nomes da multidão do exército que o narrador da Ilíada (Canto II, v. 488 a 492) admite que não cantará:
A multidão não narrarei nem nomearia se dez línguas e dez bocas tivesse, voz indestrutível e peito brônzeo tivesse, se as Olimpíades Musas, filhas de Zeus portador da égide não lembrassem quantos a Troia foram.

O cantor da Ilíada alega ser limitado pelos órgãos ligados à proferição do canto (língua, boca e peito) e pela dependência mnemônica das Musas. ${ }^{32}$ Já Píndaro, além do

\footnotetext{
${ }^{31}$ Cf. Bundy, op. cit., p. 41.

32 Cf. Brandão, J. L. Antiga Musa (arqueologia da ficção). Belo Horizonte: Faculdade de Letras da UFMG, 2005, p. 46. 


\section{nuntius antiquus}

tempo livre (que será explicado na sequência), alega ser limitado pela recepção do público. A longa listagem passaria a incomodar os ouvintes, estragando o prazer da lira e do canto suave. Não é como o narrador da Ilíada que admite sua humanidade diante da potência divina das Musas. Píndaro utiliza o recurso tradicional para valorizar sua arte ("lira e voz suave"), evidenciar seu entendimento quanto à composição de odes e quanto ao gosto do público, além de focalizar a vitória de Aristômenes depois de louvar Egina. Inclusive para citar "todo o longo discurso" das conquistas da cidade, não escolhe um verbo que indique apenas cantar ou narrar, mas ó $v \alpha \theta \dot{\varepsilon} \mu \varepsilon v$, "alçar”, que ainda propicia a ideia de elevar, pôr no alto.

Píndaro continua utilizando outro motivo tradicional, o da obrigação para com o atleta vitorioso. Segundo Bundy, no v. 34, "é o Xṕ́os devido a Aristômenes que cria a falta de tempo livre para outros assuntos". ${ }^{33}$ Para Crotty, "Píndaro enfatiza que a vitória faz com que os outros tenham a obrigação de honrá-la. Nesse sentido, a vitória é muito associada a retribuição e moralidade". ${ }^{34}$

O dever (Xṕ́os) que "corre nos pés” do poeta é a nova ode, que parte de Píndaro para o vencedor. A metáfora do dever que corre nos pés faz alusão à função do epinício, já que esta parte do chão para as alturas, em direção ao vencedor, "alado pelo engenho"

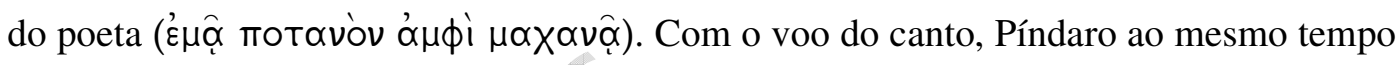
glorifica o vencedor e destaca sua própria habilidade, assumindo a responsabilidade pela qualidade do poema alado por seu engenho. É o que Gentili considera como uma nova dimensão que a consciência do próprio talento adquire com poetas como Píndaro e Baquílides. $^{35}$

Os v. 33 e 34 se assemelham aos v. finais (62 e 63) da Quinta Ístmica:

Pega a coroa para ele, traz o vestido de boa lã, E envia junto o novo hino alado.

A novidade do canto, seu caráter alado e o envio ao vencedor desse trabalho original e de qualidade, feito especificamente em homenagem a certa pessoa, valorizam o canto, que se torna também um prêmio para o vencedor.

\footnotetext{
${ }^{33}$ Cf. Bundy, op. cit., p. 42.

${ }^{34}$ Cf. Crotty, op. cit., p. 55.

${ }^{35}$ Cf. Gentili, op. cit., p. 131.
} 


\section{nuntius antiquus}

Píndaro encerra esse trecho tão metalinguístico com a palavra $\mu \alpha \chi \alpha \nu \alpha$, forma

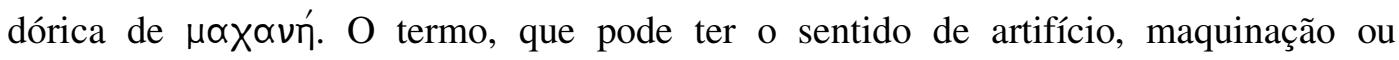
habilidade, é utilizado para se referir à arte da composição. Considerar a arte da composição como $\mu \propto \chi \alpha \nu$ r revela um autor que entende a criação poética como a montagem de uma estrutura complexa e artificial. Cada verso é cuidadosamente pensado para fazer o todo, o poema completo, funcionar bem.

No epodo, v. 35 a 40, Píndaro apresenta como justificativa para o dever que tem em relação a Aristômenes:

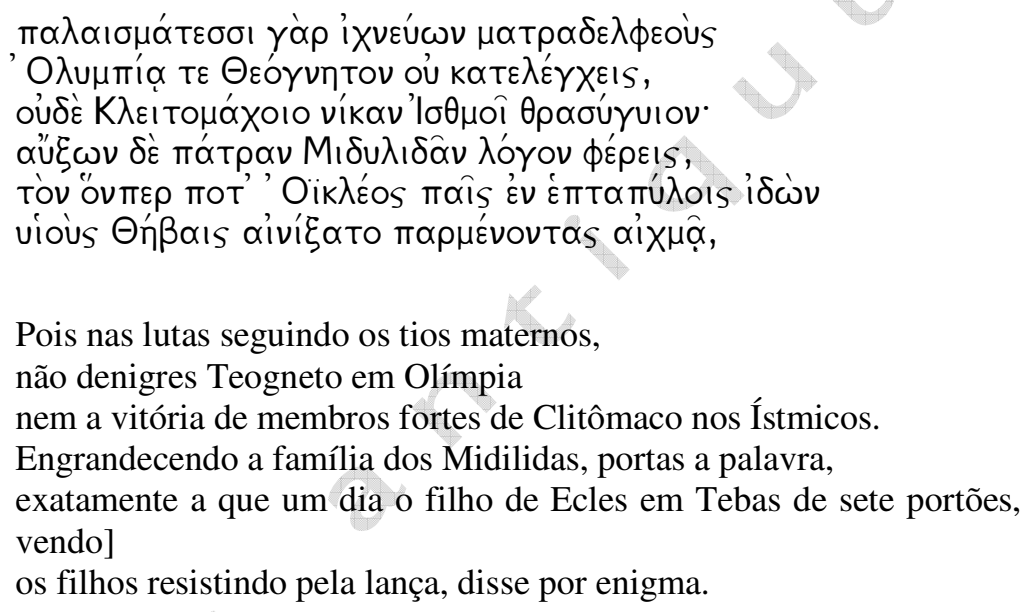

Crotty comenta que esses versos trazem claramente a noção de excelência como um valor inato. A vitória de Aristômenes é apresentada como continuação de uma herança de família e é isso o que a vincula ao mito apresentado na ode. ${ }^{36}$

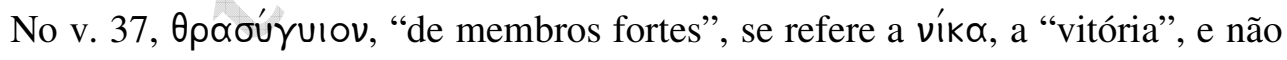
a Clitômaco, o vencedor citado. A opção por essa concordância, além de propor uma imagem menos óbvia, indica que ter membros fortes é característica não só de Clitômaco, mas de todo aquele que atinge a vitória, incluindo Aristômenes.

O v. 38 faz a ligação entre o elogio de Aristômenes e o mito. A noção

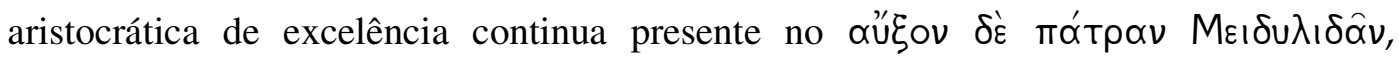
“engrandecendo a família dos Midilidas". Aư̌ $\xi \omega$, como lembra Duchemin, é uma metáfora vegetal ligada à força da vida. ${ }^{37}$ A glória de um vencedor representa o vigor de sua linhagem e, fazendo a fama da família crescer, justifica seu poder. O nome Midilo

\footnotetext{
${ }^{36}$ Cf. Crotty, op. cit., p. 18.

${ }^{37}$ Cf. Duchemin, op. cit., p. 238-239. 


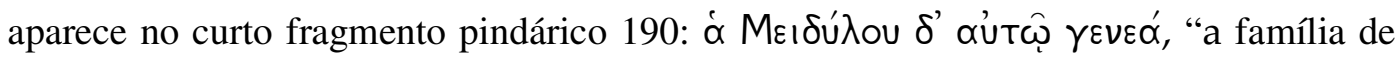
Midilo para ele". Como o fragmento também faz referência à família, é possível que

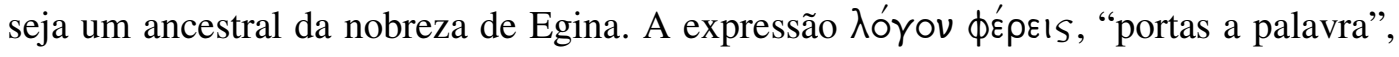
segundo Giannini, significa "reportar o discurso dito pelo mensageiro" e "Aristômenes, com seu sucesso, 'anuncia' as palavras de Anfiarau, é o mensageiro delas, no sentido que as realiza em si mesmo". 38

Píndaro abre o mito pelo anúncio das palavras de Anfiarau, o filho de Ecles, que só serão cantadas a partir do v. 44, na terceira estrofe da ode. O mito é colocado num

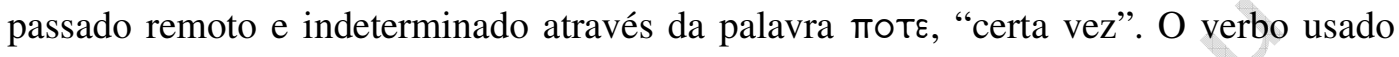
para indicar a fala de Anfiarau é óıvítTw, "dizer de forma enigmática". Píndaro justifica e engrandece os fatos do presente com a fala obscura mas densa do adivinho no passado.

O particípio 'i $\delta \omega v$, "vendo", já anuncia a importância da imagem e da visão no discurso de Anfiarau, motivado pela observação dos filhos combatendo, e nos versos que o precedem. Segundo Burnett, os episódios míticos fragmentários tornados realidade através de detalhes sensoriais são oferecidos a cada espectador como sua própria experiência fugaz do poder divino. ${ }^{39}$

A narrativa em tom um tanto épico já aparece no final do epodo: "Em Tebas de sete portões, vendo os filhos resistindo pela lança”. A terceira estrofe começa especificando o tempo que antes havia sido marcado apenas com потє (v. 41 a 43):

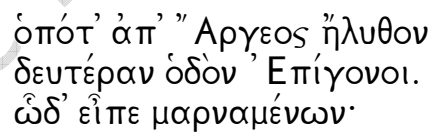

Quando de Argos vieram, em uma segunda expedição, os Epígonos. Isto disse dos que estavam combatendo:

Os Epígonos, de acordo com a Biblioteca atribuída a Pseudo-Apolodoro (3.80.1 em diante), são os filhos dos guerreiros de Argos, liderados por Alcmeão, que lutaram e caíram com Polinices na primeira expedição contra Tebas, dez anos antes. No v. 43 o discurso é anunciado finalmente. O particípio $\mu \propto \rho \nu \alpha \mu \varepsilon^{\varepsilon} \nu \omega \nu$, "combatendo", é

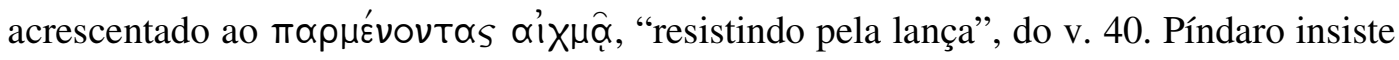

${ }^{38}$ Cf. Gentili et alii, op. cit., p. 573.

${ }^{39}$ Cf. Burnett, A. P. Pindar. London: Bristol Classical Press, 2008, p. 28. 


\section{nuntius antiquus}

em que a fala de Anfiarau acontece durante o momento em que a excelência se manifesta: na ação do combate.

Na sequência da estrofe, inicia-se o discurso (v. 44 ao 47):

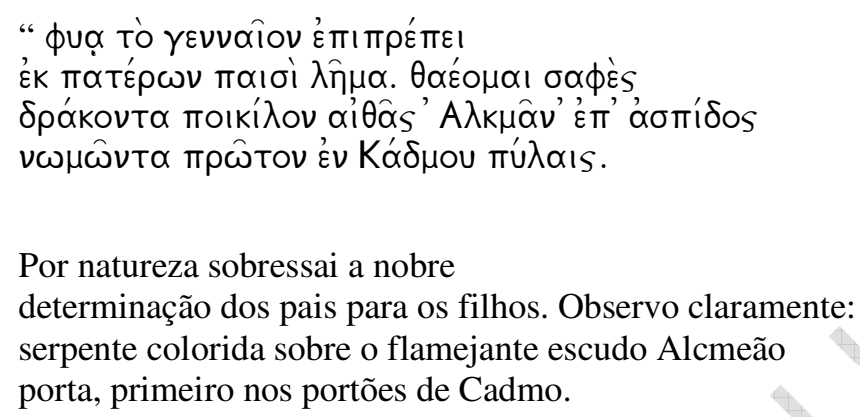

A primeira palavra, фuậ, "por natureza”, já mostra que o mito dá sequência à ideia apresentada no segundo epodo, retomando a concepção, como comenta Des Places, de uma excelência inata hereditária, que em Píndaro se opõe às virtudes aprendidas. ${ }^{40}$ Para Finley Jr.:

Na medida em que a phua de um homem é de fato a sua própria e se mostra em atos de sabedoria ou bravura, ela é uma marca da virtude humana. Entretanto, como tais atos parecem conter elementos de valor absoluto, ambos causal e, por assim dizer, existencialmente revelam os deuses, que são a origem e existência da excelência. ${ }^{41}$

Ou seja, a manifestação de excelência dos heróis, análoga à do atleta, revela a participação divina, que aparece no poema através das preces, como a primeira tríade, quarta estrofe e quarta antístrofe, e também nos momentos de reflexão sobre a existência humana, como o quarto e o quinto epodo. Giannini lembra que yevvaîov, nobre, "indica o que é 'conatural' a alguém, no sentido que não degenera de sua natureza, segundo definição de Aristóteles (Hist. Nat. 488 b 19, Rhet. 1390 b 22)" ${ }^{42}$ Para Burnett, esse discurso é importante nas odes para garotos vencedores, como é o caso, pois enfatizam a transferência da feroz ambição de uma geração para outra e, assim, relacionam a vitória a toda a casa do menino. ${ }^{43}$

\footnotetext{
${ }^{40}$ Cf. Des Places, E. Pindare et Platon. Paris: Beauchesne et ses fils, 1949, p. 66-67.

${ }^{41}$ Cf. Finley Jr., op. cit., p. 127.

${ }^{42}$ Cf. Gentili et alii, op. cit., p. 574.

${ }^{43}$ Cf. Burnett, op. cit., p. 39. 


\section{nuntius antiquus}

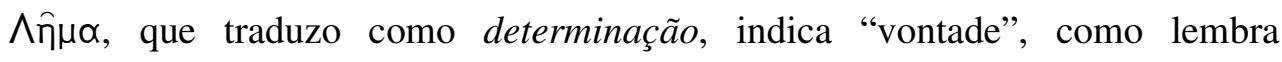
Duchemin comentando a Sexta Ístmica ${ }^{44}$ Giannini lembra que a palavra se refere à coragem na guerra. ${ }^{45}$ Anfiarau fala sobre excelência, uma vez que coragem, ou vontade de combater, é a excelência do guerreiro.

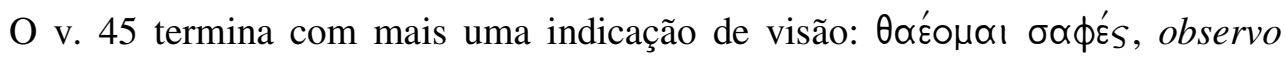
claramente. O ơфés serve como anúncio de uma descrição mais detalhada. Anfiarau não só pode observar claramente, como compõe a imagem para o ouvinte: "Serpente variegada sobre o flamejante escudo Alcmeão porta, primeiro nos portões de Cadmo". Essa é a imagem da excelência: Alcmeão, armado de forma imponente, à frente do exército e, como diz Finley, Jr., "o profeta Anfiarau observando o Alcmeão é na verdade Píndaro observando o jovem vencedor. Anfiarau e Píndaro compartilham de um pressentimento da intervenção dos deuses, que o profeta vê na morte vindoura do jovem herói e Píndaro, nos trabalhos e mudanças que seguem a vitória". ${ }^{46}$

Da terceira antístrofe até o primeiro verso do epodo, Anfiarau passa a fazer considerações sobre o rei de Argos, Adrasto (v. 48 a 56):

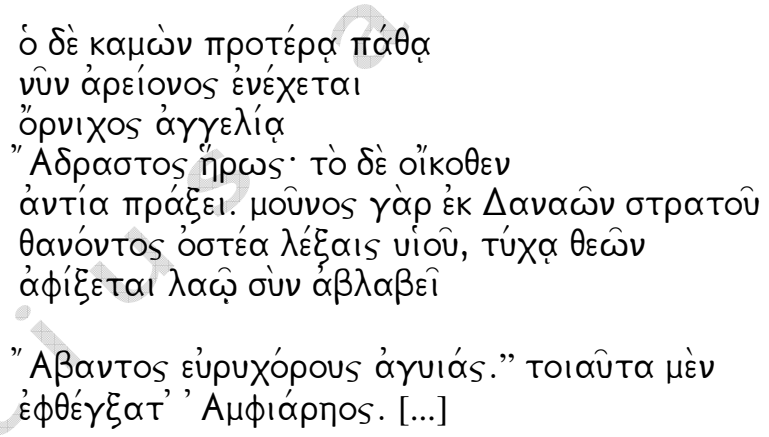

"O que quase morreu no primeiro incidente agora se mantém num anúncio de melhor auspício:

Adrasto, o herói. Em casa o contrário acontecerá, pois é o único do exército dos dânaos que os ossos recolhe, do filho morto. Com favorecimento dos deuses, chegará com o exército intacto

às ruas largas de Abas". Tais coisas disse Anfiarau. [...]

\footnotetext{
${ }^{44}$ Cf. Duchemin, op. cit., p. 175.

${ }^{45}$ Cf. Gentili et alii, op. cit., p. 574.

${ }^{46}$ Cf. Finley Jr., op. cit., p. 172.
} 
Adrasto é mencionado nominalmente apenas no v. 51, seguido de "̈pws, "herói”, que já havia aparecido no v. 29, identificando aqueles que combatem por

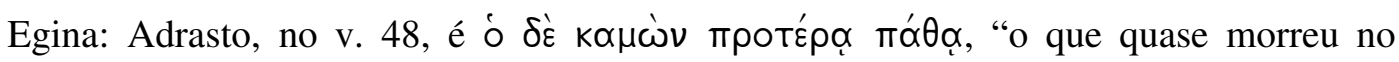
primeiro incidente". O verbo kó $\mu \nu \omega$ pode significar trabalhar, sofrer ou ficar doente. O

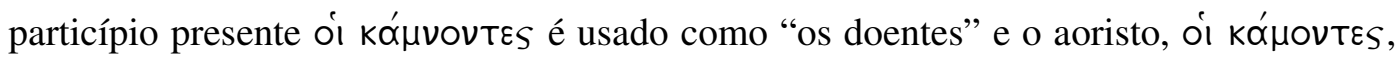
como "os mortos". O verbo indica a experiência extrema que Adrasto sofreu (de forma passiva, uma vez que a expedição é um mó́(os) na primeira expedição a Tebas.

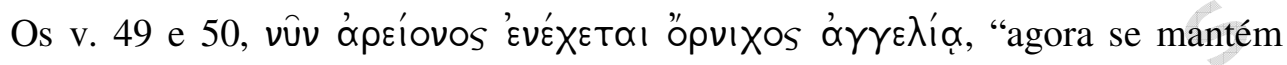
num anúncio de melhor auspício", mostram o que parece ser o ponto mais importante dessa parte da fala de Anfiarau: a variação da sorte e oscilação entre vitória e derrota na vida humana. $\mathrm{O}$ adivinho antecipa a questão que terminará no último epodo da ode. A palavra ǒpvıs significa pássaro e, devido aos presságios que eram feitos a partir das aves, ganha o significado de "auspício", palavra formada pelo radical latino auis, ave, e spicio, observar. O auspício revela novamente uma interferência de forças divinas. Adrasto perdeu a primeira guerra, mas sobreviveu e agora se encontra sob melhores auspícios.

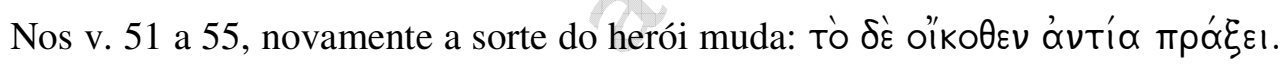

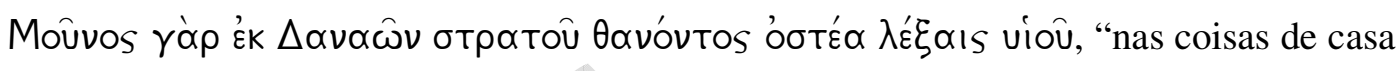
o contrário acontecerá. Pois é o único do exército dos Dânaos que os ossos recolhe, do filho morto". Apesar dos melhores presságios, Adrasto perde o filho Egialeu na guerra. Como comenta Burton, citado por Giannini, Adrasto é o oposto de Anfiarau, porque este é morto mas vê o filho ter sucesso, enquanto aquele vence a guerra, mas perde o

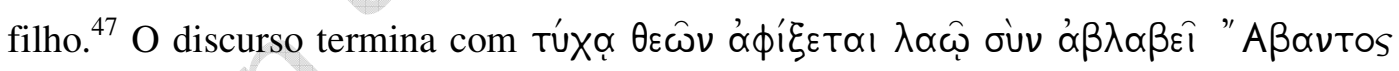

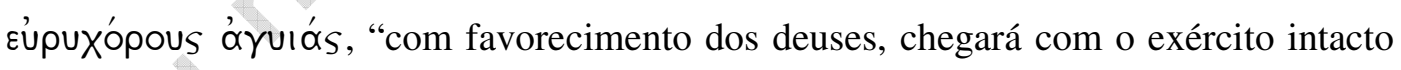
às ruas largas de Abas", explicitando a presença divina no sucesso das empreitadas humanas. A palavra túX $\propto$, que pode significar "acaso", mostra como não é possível para o humano compreender exatamente o que os deuses determinam. Segundo Crotty, essa importância dada à TúXワ ao descrever a relação entre o vencedor e sua vitória revela o movimento de uma noção de justiça simples e de retribuição, da primeira tríade, para uma visão que é mais sensível às frustrações e transtornos proporcionados

\footnotetext{
${ }^{47}$ Cf. Burton, R. W. B. Pindar's Pythian Odes. Essays in interpretation. Oxford: University Press, 1962, p. 182. 


\section{nuntius antiquus}

aos homens pelos deuses. ${ }^{48} \mathrm{O}$ próprio Adrasto, mesmo sob auspícios melhores, não deixou de ter sua cota de desgraça. Píndaro deixa bem marcado o término do discurso

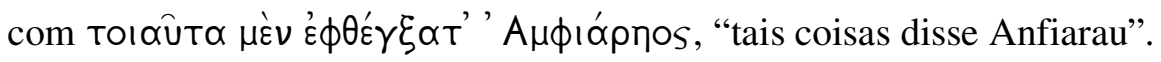

Do v. 56 ao 60, Píndaro expressa seu reconhecimento e louva Alcmeão:

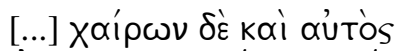

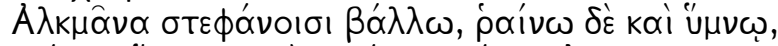

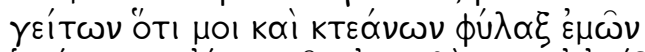

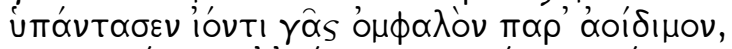

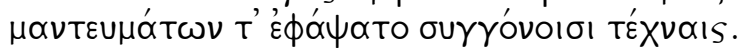

\section{[...] Alegrando-me, eu mesmo}

Alcmeão com coroas atinjo e aspirjo também um hino, porque é um vizinho para mim e das minhas posses guardião.

Veio ao meu encontro, enquanto eu ia rumo ao umbigo da terra digno de cantos.

Tocou-me com as congênitas artes dos oráculos.

Sobre esse trecho, Crotty cita Lefkowitz:

Lefkowitz argumentou que a passagem usa uma dicção que a conecta com o resto do poema e, em particular, ela demonstra a correspondência entre essa passagem e a abertura. Tal como Hesychia porta as chaves para os conselhos e as guerras, assim Alcmeão serve como protetor dos bens de Píndaro. Como ela argumenta, mesmo se nós não pudermos ter certeza da conexão histórica entre Píndaro e Alcmeão citada aqui, nós ainda podemos observar como essas conexões são usadas no poema. ${ }^{49}$

O aưtós, próprio, como sujeito dos verbos em primeira pessoa marca que o poeta retomou a palavra. "Alegrando-me, eu mesmo Alcmeão com coroas atinjo e

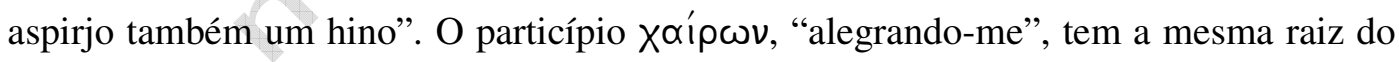
nome das Xর́pıтєs, "graças", que Píndaro associa ao embelezamento das composições. Talvez seja uma alegria relacionada com a motivação para compor uma ode. O tratamento, coroas e canto, é o mesmo dado ao vencedor nos v. 19 e 20: "Recebeu-o de Cirra o filho de Xenarces, coroado com relva do Parnaso e dórica festividade". O uso

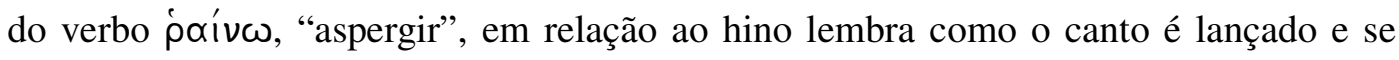
espalha, afetando aqueles que estão em volta do homenageado.

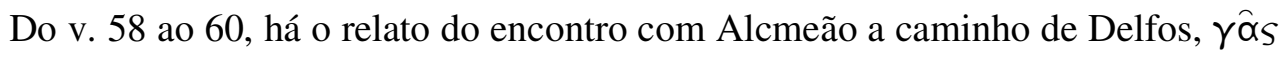

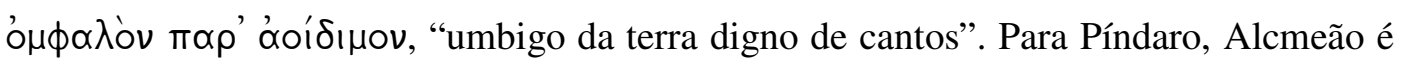

${ }^{48}$ Cf. Crotty, op. cit., p. 65.

${ }^{49}$ Cf. Crotty, op. cit., p. 22 (que remete a Lefkowitz, op. cit., 1976/ 1977). 


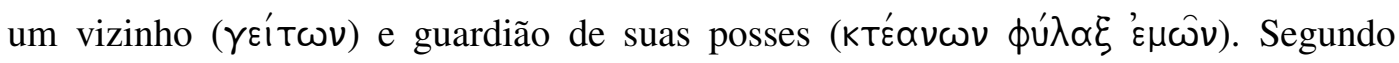
Bundy, tratar um herói como vizinho é um motivo convencional nos epinícios. ${ }^{50}$ Não necessariamente significa que existia um local de culto a Alcmeão nas redondezas de Egina ou Tebas, ao contrário do que afirmam Giannini ${ }^{51}$ e Finley Jr. ${ }^{52}$ Para Lefkowitz, as posses do poeta que Alcmeão guarda são os assuntos de sua poesia. ${ }^{53} \mathrm{Ou}$ seja, mais uma forma de mostrar a excelência do herói por meio da excelência do poeta.

Os comentadores leem esse encontro de formas diversas. Para Duchemin, o poeta associa sua alegria àquela do vencedor. ${ }^{54}$ Finley Jr., tendo em mente a estrofe e antístrofe que seguem, propõe que o relato tem um tom pessoal que mantém sua prece por uma vida de harmonia com Apolo. ${ }^{55}$ Lefkowitz indica que "o encontro do poeta com Alcmeão exemplifica uma verdade geral, da qual o fim violento dos inimigos de Hesychia mais cedo fornece uma ilustração negativa". ${ }^{56}$ Inclusive o verbo úravтó $\omega$, "vir ao encontro", aqui aparece com uma conotação positiva, um encontro amigável, ao

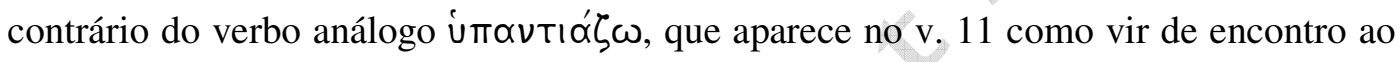
inimigo.

O encontro com Alcmeão é o artifício de Píndaro para conectar o relato mítico novamente com o presente e com o contexto de elogio e enaltecimento do vencedor.

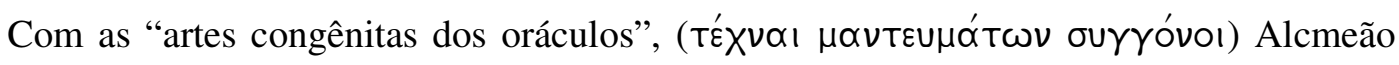
deu a Píndaro conhecer a previsão relativa à excelência de Aristômenes. Os comentadores concordam na importância do mito para a ode triunfal. Duchemin afirma que "o essencial do ensinamento do poeta se situa justamente no mito, onde a narração das conquistas lendárias ganha valor de exemplo". 57 Ela também comenta que a noção de imortalidade nos aparece como o centro indiscutível da poesia de Píndaro e que "a preocupação dominante do mito, sempre orientado ao mesmo sentido, é fazer espelhar aos olhos do vencedor dos jogos a feliz imortalidade, obtida antes dele pelo valor e virtudes heroicas daqueles em que o poeta reconhece seus modelos e como seus patronos" ${ }^{58}$ Crotty observa que os deuses estão envolvidos com a vitória desde o início

\footnotetext{
${ }^{50}$ Cf. Bundy, op. cit., p. 70.

${ }^{51}$ Cf. Gentili et alii, op. cit., p. 576.

${ }^{52}$ Cf. Finley Jr., op. cit., p. 129.

${ }^{53}$ Cf. Lefkowitz, op. cit., 1975, p. 183.

${ }^{54}$ Cf. Duchemin, op. cit., p. 90.

${ }^{55}$ Cf. Finley Jr., op. cit., p. 167.

${ }^{56}$ Cf. Lefkowitz, op. cit., 1975, p. 183.

${ }^{57}$ Cf. Duchemin, op. cit., p. 339.

${ }^{58}$ Cf. Duchemin, op. cit., p. 270. 
e que o mito indica um largo envolvimento dos deuses com a vida de Aristômenes, predizendo seu sucesso e então o propiciando. ${ }^{59}$ Burnett nega o caráter de ensinamento moral ou de exemplo heroico do relato mítico. Para ela, "em vez disso, induzem uma sensação de presença extra-humana imediata, enquanto mostram a força herdada, favor divino ou coragem individual necessariamente presente em qualquer conquista de supremacia". ${ }^{60}$ Esse, certamente, é um aspecto importante na performance da ode, contudo, como já havia escrito Jaeger, se o elogio da areta é a tarefa máxima do poeta, isso faz dele um educador. ${ }^{61}$ Portanto, o mito mostra que o vencedor apresenta a excelência inata, mas ainda assim precisa da ação divina para poder efetivamente fazer sua excelência garantir a vitória e possibilitar que, como os heróis, ele também seja digno de canto por ter sentido de algum modo a presença divina em sua vida.

\section{Referências}

ADRADOS, F. R. El mundo de la lírica griega antigua. Madrid: Alianza Editorial, 1981.

ALLEN, T. W. Homeri Ilias. Oxford: Clarendon Press, 1931.

BENVENISTE, E. Le vocabulaire des Instituitions Indo-Européennes. 2. Pouvoir, droit, religion. Paris: Les Éditions de Minuit, 1969.

BRANDÃO J. L. Antiga Musa (arqueologia da ficção). Belo Horizonte: Faculdade de Letras da UFMG, 2005.

BUNDY, E. Studia Pindarica. Los Angeles: University of California Press, 1986.

BURNETT, A. P. Pindar. London: Bristol Classical Press, 2008.

BURTON, R. W. B. Pindar's Pythian Odes. Essays in interpretation. Oxford: University Press, 1962.

CHANTRAINE, P. Dictionnaire étymologique de la Langue Grecque. Histoire des mots. Paris: Éditions Klincksieck, 1968. Tome I.

\footnotetext{
${ }^{59}$ Cf. Crotty, op. cit., p. 23.

${ }^{60}$ Cf. Burnett, op. cit., p. 41.

${ }^{61}$ Cf. Jaeger, op. cit., p. 262.
} 
CROTTY, K. Song and action. Baltimore: The Johns Hopkins University Press, 1982.

DES PLACES, E. Pindare et Platon. Paris: Beauchesne et ses fils, 1949.

DUCHEMIN, J. Pindare, poète et prophète. Paris: Les Belles Lettres, 1955.

FINLEY JR, J. H. Pindar and Aeschylus. Cambridge: Havard University Press, 1966.

GENTILI, B. Poetry and its public in Ancient Greece. From Homer to the fifth century. Translated with an introduction by A. Thomas Cole. London: Johns Hopkins Press, 1990.

GENTILI, B.; ANGELI-BERNARDINI, P.; CINGANO, E.; GIANNINI, P. (org.). Pindaro: Le Pitiche. Verona: Arnoldo Mondadori, 1995.

GERNET, L. Recherches sur le développement de la pensée juridique et morale en Grèce. Paris: Albin Michel, 2001.

JAEGER, W. W. Paideia: a formação do homem grego. Tradução de Artur M. Parreira. São Paulo: Martins Fontes, 2001.

LEFKOWITZ, M. Influential fictions in the scholia to Pindar's "Pythian 8". Classical Philology. Chicago, vol. LXX, n. 3, p. 173-185, jul. 1975.

$1976 / 1977$.

Pindar's “Pythian 8”. The Classical Journal. Northfield, n. 72, p. 209-221,

LOPES, A. O. O. D. L'effectivité improbable. Une étude de l'adverbe "rê̂a", de l'adjectif "chalepós" et des termes qui en dérivent dans les poèmes homériques. Tese de doutorado inédita em filosofia. Strasbourg: Université Marc Bloch, 2009.

MAEHLER, H. (post B. Snell) (org.). Pindari carmina cum fragmentis. Leipzig: Teubner, 1971.

von der MÜHLL, P. Homeri Odyssea. Basileia: Helbing \& Lichtenhahn, 1962.

MURRAY, G (org.). Aeschyli tragoediae. Oxford: Clarendon Press, 1955.

SOLMSEN, F. (org.). Hesiodi opera. Editado por F. Solmsen. Oxford: Clarendon Press, 1970.

WAGNER, R. Apollodori Bibliotheca (Mythographi Graeci, I). Leipzig: Teubner, 1894. 
WEST, M. L. Hesiod. Theogony. Oxford: Clarendon Press, 1966.

. (org.) Iambi et elegi Graeci. Oxford: Clarendon Press, 1972. Vol. II. Delectus ex iambis et elegis graecis. Oxford: University Press, 1993.

WILAMOWITZ-MOELLENDORFF, U. F. W. Pindaros. Berlin: Weidmann, 1922. 